\title{
Planning of distribution substations, feeders and sectionalizing switches using heuristic algorithms
}

\author{
Y-Y Hsu \\ Department of Electrical Engineering. National Taiwan \\ University, Taipei, Taiwan, Republic of China
}

\author{
Y Jwo-Hwu \\ Department of Electrical Engineering, Kung Shan \\ Institute of Technology and Commerce, Tainan. \\ Taiwan, Republic of China
}

\begin{abstract}
The distribution system planning problem is divided into three subproblems: the substation planning problem, the feeder planning problem and the sectionalizing switch planning problem. Heuristic search algorithms are developed for each subproblem. In the substation planning problem, the locations of the substations are determined based on the specified number of substations. Then, the feeder network is determined based on the requirements of minimum investment cost and maximum available configurations in future system operation. Finally, the sectionalizing switches are placed at locations where feeder reconfiguration is most probable. Therefore, a major feature of the proposed planning algorithm is that the need of network reconfiguration in future system operation is taken into account. The effectiveness of the proposed algorithm is demonstrated by the planning of a distribution system in Taipei, Taiwan. It is concluded from the results in this work that proper distribution plans can be reached by the proposed method in a very efficient manner. Copyright $(\mathbb{C}) 1996$ Elsevier Science Ltd.
\end{abstract}

Keywords: distribution planning, heuristic algorithms, substation planning, feeder planning, sectionalizing switch planning, distribution automation

\section{Introduction}

In the planning of a distribution system, one is concerned about the determination of proper numbers and locations of substations, feeders and sectionalizing switches based on the forecasted loads. A common practice in distribution planning is to minimize the total investment cost subject

Received 9 March 1995; revised 29 June 1995; accepted 3 August 1995 to the constraints of voltage drop limits, transformer and feeder capacity limits, etc ${ }^{1-16}$. Feeder and transformer losses are also included in the objective function of distribution planning in some works.

To supply power to all load points in the system, a radial feeder configuration can be employed. Radial feeder structure is simple and requires a minimal length of feeders ${ }^{4-6}$. In addition, the protective devices in a distribution system with a great number of components can be easily coordinated if the system structure is radial. Therefore, a distribution system is usually configured radially in normal system operation in order to achieve proper coordination of the protective devices.

However, the system topology must be changed through feeder reconfiguration when one tries to restore the electricity service in unfaulted regions following an outage event in the system. Even when all components are normal and the system is in normal operation, feeder reconfiguration is still necessary in order to achieve load balancing and loss reduction ${ }^{17-22}$. In a distribution system where all switches are operated manually, feeder reconfiguration may be conducted once per week, once per month or once per season based on the forecasted loads in that particular period. However, feeder reconfiguration may be conducted more frequently, e.g., once per day, in an automated distribution system where the switches are operated via remote control and the section loads are monitored and recorded by computers in the distribution dispatch and control centre.

To make feeder reconfiguration possible, a loop-type network structure must be established at the planning stage. Then, some tie switches are normally opened in order to achieve radial feeder configuration in normal system operation. It is obvious that more feeder configurations can be achieved during system operation if we put more sectionalizing switches and more feeder 
However, more switches and feeders would require higher investment costs. A trade-off must be made between the benefits gained in the operation stage and the costs required in the planning and construction stage resulting from the adoption of more switches and feeder branches in order to reach a proper distribution plan.

In the present work, we try to determine a proper distribution plan with a minimum number of switches and feeder branches which can meet the need of feeder reconfiguration in normal system operation. The overall distribution problem is divided into three subproblems, i.e., the substation planning problem, the feeder planning problem and the sectionalizing switch planning problem. Heuristic algorithms based on operators' experience are developed for each subproblem in order to reach the desired planning results. In order to demonstrate the effectiveness of the proposed heuristic algorithms, distribution planning is conducted on a distribution system in Taipei, Taiwan. It is found that a proper distribution plan can be achieved very efficiently by the proposed algorithms.

\section{Problem formulation}

Consider a distribution system with 12 load points $\mathrm{L}_{0}, \mathrm{~L}_{1}, \ldots, \mathrm{L}_{11}$, as shown in Figure 1a. If the load points are supplied with power from the two feeders $f_{0}$ and $f_{1}$ as shown in Figure la, the network structure is simple and radial. The investment cost is low in this case. However, reconfigurations for line loss reduction or voltage correction under normal system operation and restoration after a fault are impossible.

The network in Figure $1 \mathrm{~b}$ is a loop-structure configuration. In normal operation, a certain tie switch such as switch $\mathrm{S}_{6}$ is opened to make the system radial. To reconfigure the network, the open tie switch is moved to some other places such as $S_{5}$ or $S_{7}$. Only a small number of alternative configurations are possible for the network in Figure 1b. To have more possible configurations, more feeder sections and switches can be placed to form the network of Figure 1c. However, the investment cost may be too high. As a trade-off between the investment cost and the availability of feeder configurations, the network in Figure 1d may be a good choice.

From the simple distribution system in Figure 1, the following observations are made.

(1) It is impossible to perform reconfiguration on a radial network.

(2) The network must be planned as a loop for the purpose of feeder reconfiguration in system operation.

(3) A network with a great number of feeder sections and sectionalizing switches can offer more possible configurations in system operation. The operational cost will be reduced. However, the investment cost is high in this case. A trade-off between the investment cost and operation cost must be made.

With these observations in mind, we can proceed to give a definition of the distribution planning problem under study.

\section{The distribution planning problem}

Given the forecast loads, determine the locations, installed capacities and total number of substations, the feeder network structure and the locations and total number of sectionalizing switches such that all load
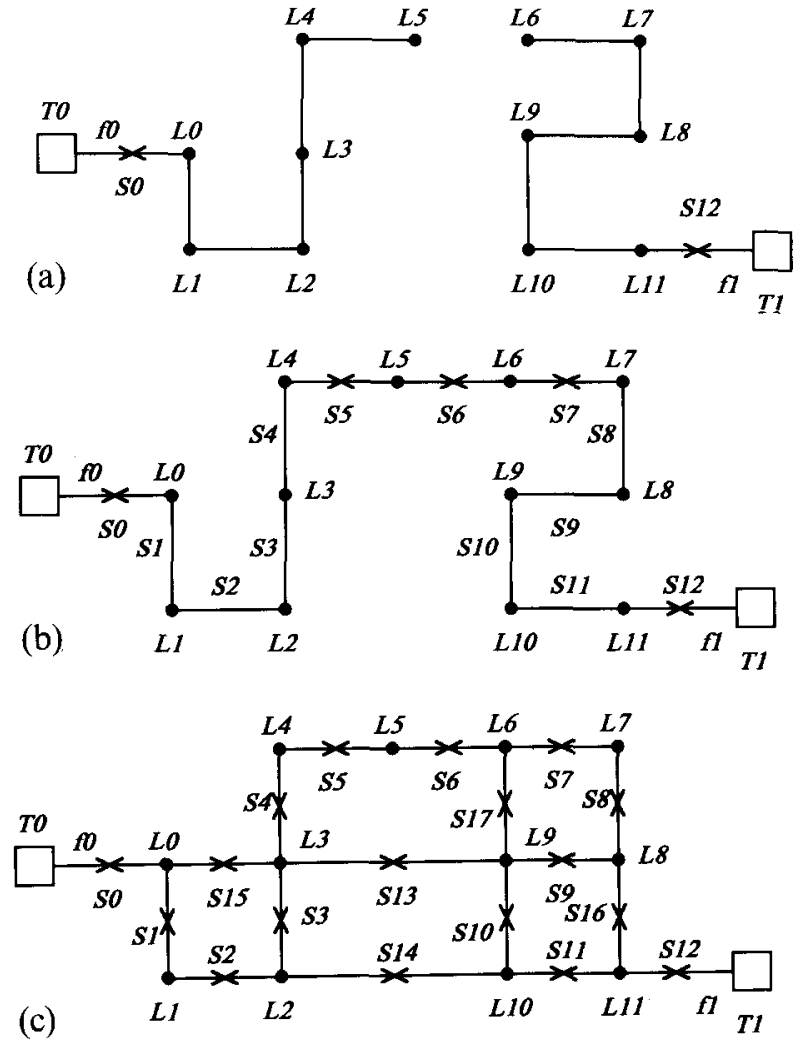

(d)

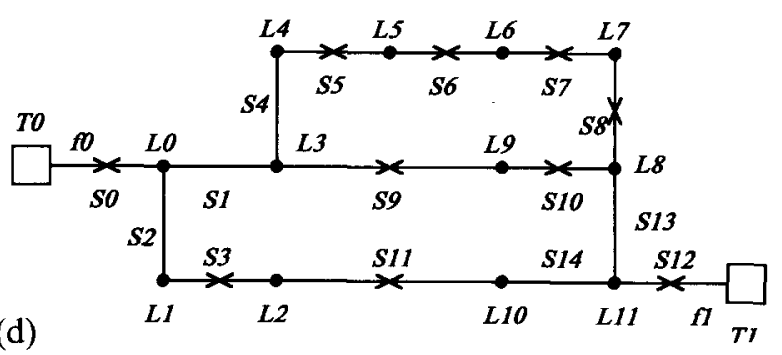

Figure 1. A simple distribution system. (a) A radial network. (b) A simple loop-type network. (c) A network with a great number of feeder sections and switches. (d) A network with a reasonable number of feeder sections and switches. Legend: $\square$ Ti: main transformer $\mathrm{Ti}$; $\mathrm{Si}$ : candidate switch position; $\mathrm{x}$ : switch; fi: feeder $\mathrm{i}$; Li: load point $\mathrm{Li}$

points are supplied power and no components are overloaded. The investment cost must be minimized while satisfactory feeder reconfiguration can be achieved in future system operation.

\section{The proposed distribution planning algorithm}

Figure 2 depicts the block diagram of the proposed planning algorithm. The algorithm proceeds as follows.

Step 1 . Specify the desired number of substations.

Step 2. Use the substation planning algorithm to be described in Section IV to determine the installed capacities and locations of substations.

Step 3. Use the feeder planning algorithm to be described in Section $\mathrm{V}$ to determine the feeder network configurations.

Step 4. Use the sectionalizing switch planning algorithm to be described in Section VI to determine the locations of sectionalizing switches. 


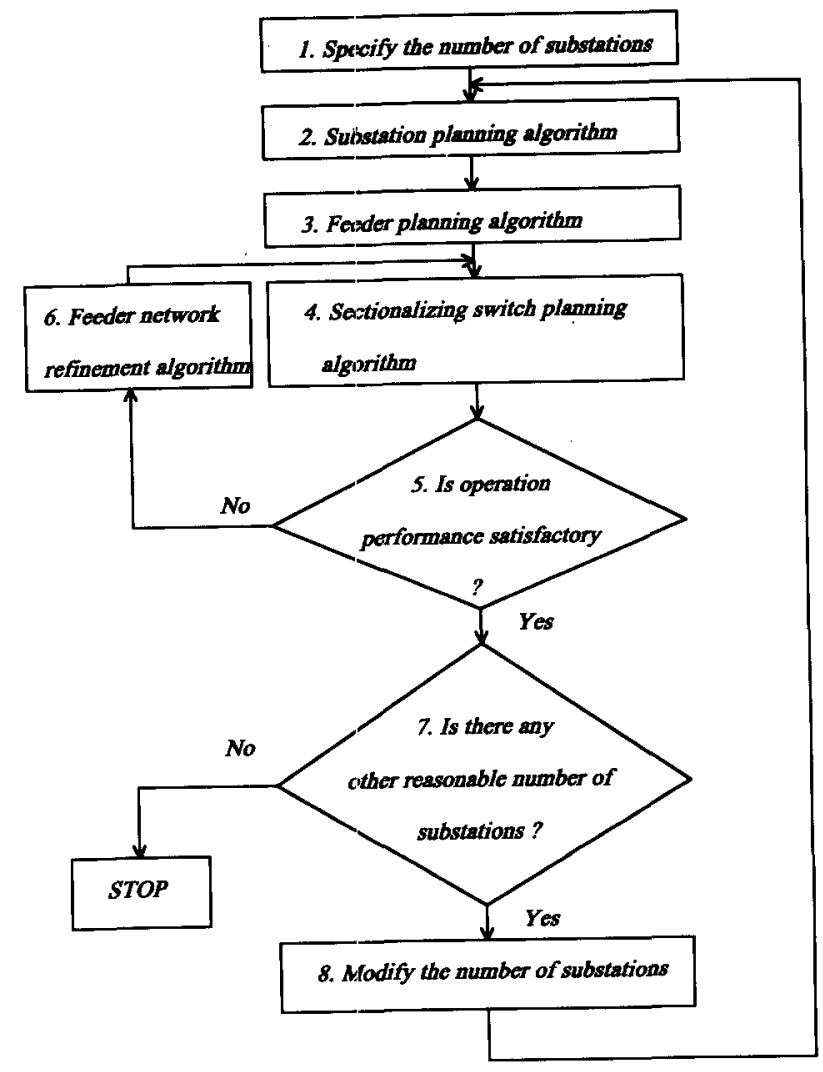

Figure 2. The proposed distribution planning algorithm

Step 5. Check if there are enough possible feeder network configurations for the purpose of loss reduction and voltage correction in future system operation. If the answer is yes, proceed to step 7. If the answer is no, go to step 6.

Step 6. Use the feeder network refinement algorithm to be described in Section VII to modify the feeder network configuration and go back to step 4 .

Step 7. Check if there is any other possible number of substations. If the answer is no, print out the distribution plan with minimum investment cost. Otherwise go to step 8.

Step 8. Modify the number of substations and go back to step 2.

\section{The substation planning algorithm}

Before the substation planning algorithm is introduced, some useful symbols are defined.

$N_{\text {SUB }}$
$N_{\text {SPEC }}$
$R L\left(L_{i}\right)$
$R C\left(b_{i}\right)$

number of substations

specified number of substations

rated load of load point $L_{i}(\mathrm{~A})$

sum of rated loads of load points within block $b_{i}(A)$

$E R C\left(\mathrm{~b}_{i}\right) \quad$ expanded rated capacity of block $\mathrm{b}_{i}(\mathrm{~A})$

$R C S\left(\mathrm{~b}_{i}\right)$ rated capacity of the substation located at block $b_{i}(A)$

$L O A D_{\text {system }}$ total load of the system (A)

$R M \quad$ percentage reserve margin of the system

As shown in Figure 3, the algorithm for substation planning proceeds as follows.

Step 1. Divide the entire service area into a number of blocks $b_{i}$.

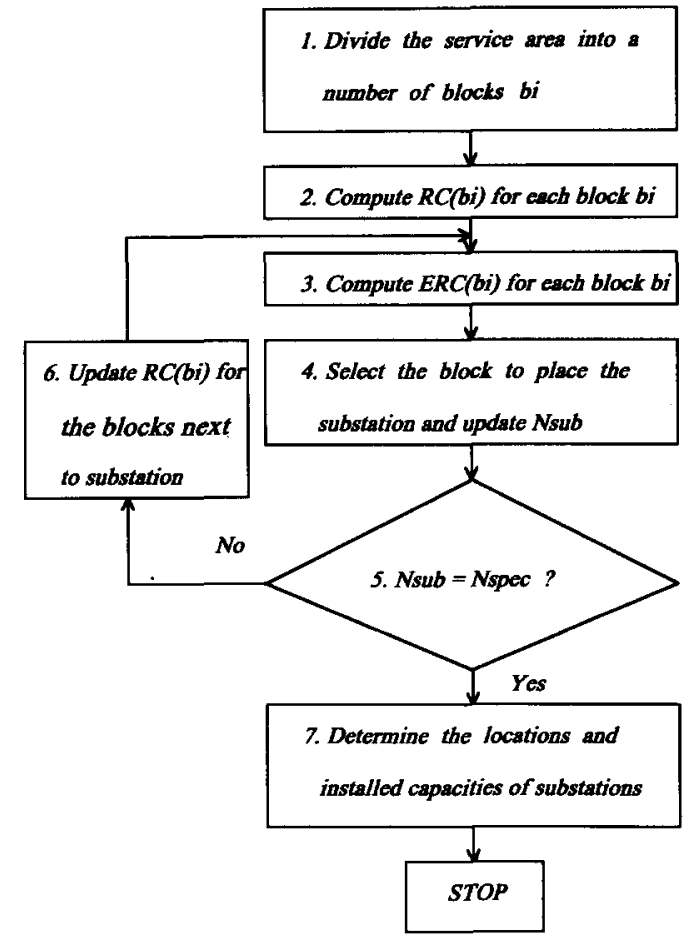

Figure 3. The substation planning algorithm

Step 2. Compute the sum of rated loads of load points within block $b_{i}$ as follows.

$$
R C\left(\mathrm{~b}_{i}\right)=\sum_{L_{k}} R L\left(L_{k}\right), L_{k} \text { is within block } \mathrm{b}_{i} .
$$

Step 3. Compute the expanded rated capacity of block $b_{i}$ as follows.

$$
E R C\left(\mathrm{~b}_{i}\right)=R C\left(\mathrm{~b}_{i}\right)+\sum_{\mathrm{b}_{k}} R C\left(\mathrm{~b}_{k}\right)
$$

where $b_{k}$ is a block next to block $b_{i}$.

Step 4. Select the block with maximum expanded rated capacity $E R C\left(\mathrm{~b}_{i}\right)$ as the block for placing a substation. The main reason for locating a substation at such a block is that we want to put a substation as close to the load centre as possible. Define $R C S^{\prime \prime}\left(\mathrm{b}_{i}\right)=E R C\left(\mathrm{~b}_{i}\right)$.

Step 5. Check if the number of substation $N_{\text {SUB }}$, is equal to $N_{\mathrm{SPEC}}$, the specified number of substations. If the answer is yes, proceed to step 7 to determine the locations and installed capacities of substations. Otherwise, go to step 6 to update $R C\left(\mathrm{~b}_{i}\right)$ for the blocks next to the substation.

Step 6. Set $R C\left(\mathrm{~b}_{i}\right)$ to be zero for the block $\mathrm{b}_{i}$ selected in step 4 as the substation location. Set $R C\left(\mathrm{~b}_{k}\right)$ to be equal to one half of its original value for each block $b_{k}$ next to block $b_{i}$. Go back to step 3 .

Step 7. Determine the locations and rated capacities of substations. If there is only one load point within the block $b_{i}$ selected for locating a substation, place the substation at the geometric centre of block $b_{i}$. If there is more than one load point within block $b_{i}$, locate the substation at the geometric centre of these load points within block $b_{i}$. 


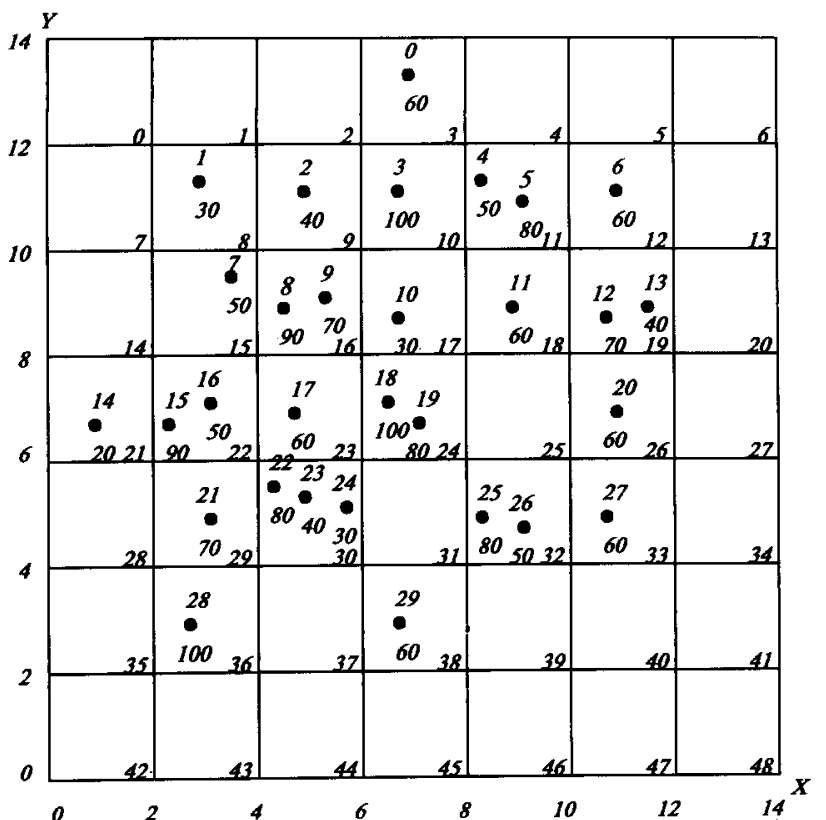

Figure 4. Load points for the study distribution system $A$

Legend : : : the rated current for load point $A$ is $B$ B
The rated capacity of the substation located at block $\mathrm{b}_{i}$, $R C S\left(\mathrm{~b}_{i}\right)$, is computed using the expression

$$
\begin{aligned}
R C S^{\prime}\left(\mathrm{b}_{i}\right) & =\frac{L O A D_{\text {system }}}{1-R M} \times \frac{R C S^{\prime \prime}\left(\mathrm{b}_{i}\right)}{\sum R S C^{\prime \prime}\left(\mathrm{b}_{i}\right)} \\
R S C\left(\mathrm{~b}_{i}\right) & =\left\{R C S^{\prime}\left(\mathrm{b}_{i}\right)\right\}
\end{aligned}
$$

where $\left\{R C S^{\prime}\left(b_{i}\right)\right\}$ is the smallest integer multiple of the rated current of a main transformer which is greater than or equal to $R C S^{\prime}\left(\mathrm{b}_{i}\right)$. For example, $R C S\left(\mathrm{~b}_{i}\right)$ will be $1200 \mathrm{~A}$ if $R C S^{\prime}\left(\mathrm{b}_{i}\right)$ is $1050 \mathrm{~A}$ and the rated current of a main transformer is $600 \mathrm{~A}$.

Let us demonstrate the procedures of the algorithm by an example.

\section{Example 1 Determination of the locations and installed capacities of substations}

Consider a distribution system as shown in Figure 4. There are 30 load points $\left(\mathrm{L}_{0}, \mathrm{~L}_{1}, \ldots, \mathrm{L}_{29}\right)$. The locations, rated loads and load types of these load points are given in Table 1.

Let the specified number of substations be 2. In step 1, the entire service area is divided into 49 blocks, $b_{0}, b_{1}, \ldots, b_{48}$. In step 2 , the sum of rated loads of load points within block $b_{i}$ is computed using equation (1). For example,

$$
R C\left(\mathrm{~b}_{11}\right)=R L\left(\mathrm{~L}_{4}\right)+R L\left(\mathrm{~L}_{5}\right)=50+80=130
$$

\begin{tabular}{|c|c|c|c|c|c|}
\hline $\begin{array}{l}\text { Load point } \\
\text { number }\end{array}$ & $\begin{array}{l}\text { Location } \\
\text { (block) }\end{array}$ & $\begin{array}{l}X \text {-coordinate } \\
X_{i}\end{array}$ & $\begin{array}{l}Y \text {-coordinate } \\
Y_{i}\end{array}$ & $\begin{array}{l}\text { Installed capacity } \\
\text { (A) }\end{array}$ & Type* \\
\hline 0 & 3 & 6.7 & 13.4 & 60 & 1 \\
\hline 1 & 8 & 3.1 & 11.3 & 30 & 1 \\
\hline 2 & 9 & 5.1 & 11.2 & 40 & 3 \\
\hline 3 & 10 & 6.7 & 10.8 & 100 & 2 \\
\hline 4 & 11 & 8.5 & 11.5 & 50 & 1 \\
\hline 5 & 11 & 9.5 & 11.2 & 80 & 3 \\
\hline 6 & 12 & 11.1 & 10.8 & 60 & 3 \\
\hline 7 & 15 & 3.5 & 9.8 & 50 & 2 \\
\hline 8 & 16 & 4.7 & 9.0 & 90 & 2 \\
\hline 9 & 16 & 5.4 & 9.7 & 70 & 3 \\
\hline 10 & 17 & 7.1 & 9.1 & 30 & 1 \\
\hline 11 & 18 & 8.9 & 9.4 & 60 & 2 \\
\hline 12 & 19 & 10.9 & 9.0 & 70 & 3 \\
\hline 13 & 19 & 11.6 & 9.6 & 40 & 2 \\
\hline 14 & 21 & 1.1 & 7.0 & 20 & 2 \\
\hline 15 & 22 & 2.9 & 6.7 & 90 & 1 \\
\hline 16 & 22 & 3.1 & 7.7 & 50 & 3 \\
\hline 17 & 23 & 4.7 & 7.0 & 60 & 1 \\
\hline 18 & 24 & 6.8 & 7.4 & 100 & 3 \\
\hline 19 & 24 & 7.3 & 6.7 & 80 & 3 \\
\hline 20 & 26 & 11.2 & 7.0 & 60 & 3 \\
\hline 21 & 29 & 3.2 & 5.2 & 70 & 3 \\
\hline 22 & 30 & 4.6 & 5.5 & 80 & 2 \\
\hline 23 & 30 & 4.9 & 4.8 & 40 & 1 \\
\hline 24 & 30 & 5.5 & 4.4 & 30 & 1 \\
\hline 25 & 32 & 8.8 & 4.9 & 80 & 2 \\
\hline 26 & 32 & 9.2 & 4.6 & 50 & 3 \\
\hline 27 & 33 & 10.7 & 5.3 & 60 & 2 \\
\hline 28 & 36 & 2.8 & 2.9 & 100 & 1 \\
\hline 29 & 38 & 6.9 & 2.8 & 60 & 1 \\
\hline
\end{tabular}

Table 1. Load point data 
In step 3, the expanded rated capacity is computed using equation (2). For example,

$$
\begin{aligned}
E R C\left(\mathrm{~b}_{0}\right)= & R C\left(\mathrm{~b}_{0}\right)+R C\left(\mathrm{~b}_{1}\right)+R C\left(\mathrm{~b}_{7}\right)+R C\left(\mathrm{~b}_{8}\right) \\
= & 0+0+0+30=30 \\
E R C\left(\mathrm{~b}_{8}\right)= & R C\left(\mathrm{~b}_{8}\right)+R C\left(\mathrm{~b}_{0}\right)+R C\left(\mathrm{~b}_{1}\right)+R C\left(\mathrm{~b}_{2}\right) \\
& +R C\left(\mathrm{~b}_{7}\right)+R C\left(\mathrm{~b}_{9}\right)+R C\left(\mathrm{~b}_{14}\right) \\
& +R C\left(\mathrm{~b}_{15}\right)+R C\left(\mathrm{~b}_{16}\right) \\
= & 30+0+0+0+0+40+0+50+160 \\
= & 280
\end{aligned}
$$

In step 4 , block $b_{23}$ is selected for placing a substation $\mathrm{SUB}_{0}$ because $\operatorname{ERC}\left(\mathrm{b}_{23}\right)=840$ is the greatest.

In step 5, as $N_{\text {SUB }}=1$ which is less than $N_{\text {SPEC }}(=2)$, go to step 6. Now, set $R C\left(\mathrm{~b}_{23}\right)=0, R C\left(\mathrm{~b}_{15}\right)=50 / 2=25$, $R C\left(\mathrm{~b}_{16}\right)=80, R C\left(\mathrm{~b}_{17}\right)=15, R C\left(\mathrm{~b}_{22}\right)=70, R C\left(\mathrm{~b}_{24}\right)=$ $90, \quad R C\left(\mathrm{~b}_{29}\right)=35, \quad R C\left(\mathrm{~b}_{30}\right)=75, \quad R C\left(\mathrm{~b}_{31}\right)=0$. Go back to step 3 to recompute ERC $\left(b_{i}\right)$.

In step 4 , block $b_{18}$ is selected to locate the second substation $\mathrm{SUB}_{1}$ in because $E R C\left(\mathrm{~b}_{18}\right)=625$ is the greatest. As $N_{\mathrm{SUB}}(=2)$ is now equal to $N_{\mathrm{SPEC}}$, go to step 7. In step 7, there is only one load point for either block $b_{23}$ or block $b_{18}$. Therefore, the location for substations $\mathrm{SUB}_{0}$ and $\mathrm{SUB}_{1}$ are chosen to be at the geometric centres of blocks $b_{23}$ and $b_{18}$, respectively. When expressed in $X$-coordinates and $Y$-coordinates, the two substations are placed at $(5,7)$ and $(9,9)$, respectively. As for the capacities of the two substations, these are computed using equations (3) and (4).

$$
\begin{aligned}
R C S^{\prime}\left(\mathrm{SUB}_{0}\right)= & R C S^{\prime}\left(\mathrm{b}_{23}\right)=\frac{1860}{1-0.3} \times \frac{840}{840+625} \\
& =1523.55 \\
R C S^{\prime}\left(\mathrm{SUB}_{1}\right)= & R C S^{\prime}\left(\mathrm{b}_{18}\right)=\frac{1860}{1-0.3} \times \frac{625}{840+625} \\
& =1133.59 \\
R C S\left(\mathrm{SUB}_{0}\right)= & 1800=3 \times 600=6 \times 300 \\
R S C\left(\mathrm{SUB}_{1}\right)= & 1200=2 \times 600=4 \times 300
\end{aligned}
$$

Note that the rated currents of a main transformer and a feeder are assumed to be $600 \mathrm{~A}$ and $300 \mathrm{~A}$, respectively. Thus, there are three main transformers and six feeders in substation $\mathrm{SUB}_{0}$ located at block $\mathrm{b}_{23}$. Similarly, there are two main transformers and four feeders in substation SUB $_{1}$ located at block $b_{18}$.

\section{The feeder planning algorithm}

As mentioned before, the feeder network structure must be loop-type for the purpose of feeder reconfiguration in system operation. As the investment cost of feeders is proportional to feeder length, the objective of the feeder planning subproblem is to construct a loop-type feeder network with minimum feeder length in order to achieve minimum investment cost. As there are a large number of load points in the system, an exhaustive search of possible configurations would be computationally inefficient. In this section, a heuristic search algorithm as shown in Figure 5 is proposed in order to reach the desired feeder network. The algorithm proceeds as follows.

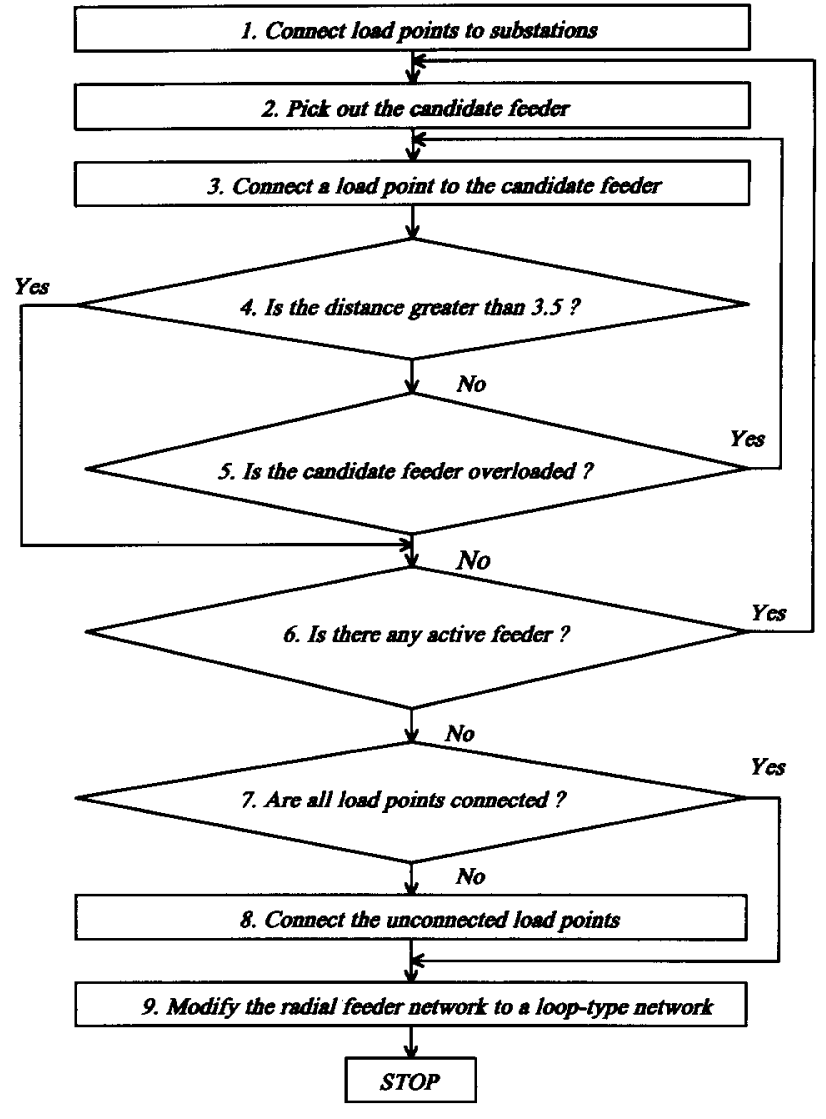

Figure 5. The heuristic search algorithm for feeder planning

Step 1. Connect a number of load points closest to a substation to form the desired feeders supplied power from the substation. Note that the number of load points must be equal to the number of feeders from the substation.

Step 2. Select the feeder with maximum reserve capacity as the candidate feeder.

Step 3. For any pair of a connected load point on the candidate feeder and an unconnected load point, find the pair of load points with minimum distance. Connect the two load points to form a new feeder section.

Step 4. Check if the length for the feeder section formed in step 3 is greater than 3.5 (the value specified by the planner). If the answer is yes, remove the feeder section and label the candidate feeder as an inactive feeder. Go to step 6 . If the answer is no, go to step 5 .

Step 5. Check if the candidate feeder is overloaded. If the answer is yes, remove the feeder section and go back to step 3. Otherwise, go to step 6 .

Step 6. If there is any feeder which is not yet labelled as an inactive feeder, go back to step 2 . Otherwise, proceed to step 7 .

Step 7. Check if all load points have been connected. If the answer is yes, go to step 9. Otherwise go to step 8.

Step 8. Connect an unconnected load point to the closest connected load point.

Step 9. The feeder network structure is radial up to now. For the purpose of feeder reconfiguration in future system operation, we need a loop-type feeder network. To reach such a feeder network, 
the load point at the end of a feeder is connected to the load point which is closest to the particular load point and is supplied with power from a separate feeder.

\section{The sectionalizing switch planning algorithm}

For any distribution system under a given load condition, there exists a near-optimal feeder configuration to achieve load balancing and loss reduction under the constraints of voltage drop and capacity limits of transformers and feeders. To reach such a near-optimal feeder configuration, the feeder configuration is modified by closing some tie switches and opening a set of corresponding switches. In normal system operation, the feeder reconfiguration must be conducted at the frequency of once per month, once per week, twice per day, or even once per hour (for an automated system), to meet the ever-changing load patterns. A desirable plan of sectionalizing switches must provide the distribution system with all possible near-optimal feeder configurations in future system operation using as few switches as possible.

While an exhaustive search of all possible configurations would provide the most accurate solution, it takes a very long time to get the desirable solutions, so making the approach unrealistic. On the other hand, heuristic algorithms will give approximate solutions in a very efficient manner. In a recent work completed by the authors $^{23}$, the load patterns are divided into several typical types and the system is divided into several switchable regions. Only the switches within switchable regions are allowed to be operated for feeder reconfiguration. Thus, by counting the total number of possible feasible switch operations within the switchable regions for the typical load patterns during the study period, we can evaluate the performance of feeder reconfiguration. It is believed that the system operators will have more opportunities to perform feeder reconfiguration in order to meet the time-varying load patterns if there are more possible switch operations.

In the present work, a novel approach called the key position method as shown in Figure 6 is proposed to place switches at proper locations. Before the algorithm is introduced, some useful symbols are defined.

$\mathrm{SET}_{i}$ the set of open switches for the near-optimal feeder configuration for load pattern $i$.

$\mathrm{SET}_{\text {open }}$ the union of $\mathrm{SET}_{i}$ for load pattern $i$ during the study period.

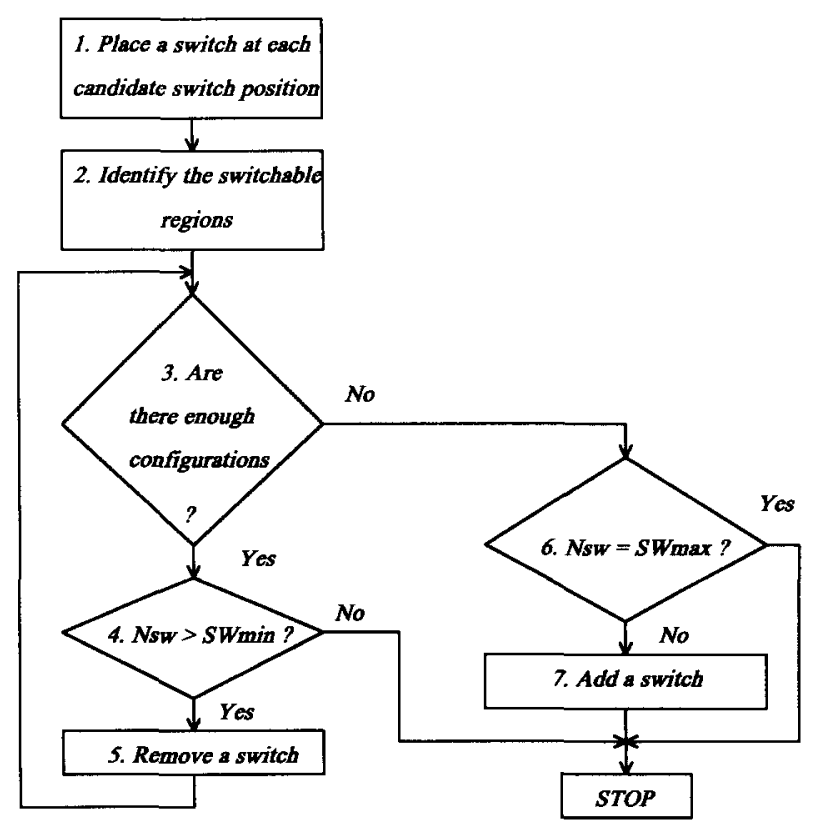

Figure 6. The key position method for sectionalizing switch planning

$S W_{\max }$ the total number of candidate switch positions in the distribution system under consideration.

$S W_{\min }$ the minimum number of switches for feeder reconfiguration.

$N_{\text {Sw }}$ the total number of switches up to now.

The algorithm proceeds as follows.

Step 1. Place a switch at each candidate switch position. Note that $N_{\mathrm{SW}}=S W_{\max }$ at the present time.

Step 2. Ideritify the switchable regions by using the algorithm in Reference 23.

Step 3. If there are enough feeder configurations for the purpose of feeder reconfiguration in system operation, proceed to step 4 . Otherwise, go to step 6.

Step 4. If $N_{\mathrm{SW}}=S W_{\min }$, print out the results and stop. If $N_{\mathrm{SW}}>S W_{\min }$, go to step 5 to decrease the total number of switches.

Step 5. Remove the switch which appears in set SET $i$ for load pattern $i$ the smallest number of times and go back to step 3 to check if there are enough feeder configurations.

Step 6. If $N_{\mathrm{SW}}=S W_{\max }$, stop. Otherwise, proceed to step 7 .

Step 7. Restore the switch just removed in step 5 and then stop.

Table 2. Summary of typical load patterns (A) and installed capacities (A) of load points in Figure 1b

\begin{tabular}{|c|c|c|c|c|c|c|c|c|c|c|c|c|c|}
\hline Year & $\begin{array}{l}\text { Typical } \\
\text { load pattern }\end{array}$ & 0 & 1 & 2 & 3 & 4 & 5 & 6 & 7 & 8 & 9 & 10 & 11 \\
\hline $1 \mathrm{st}$ & 0 & 50 & 30 & 20 & 15 & 5 & 10 & 10 & 10 & 15 & 30 & 45 & 35 \\
\hline $1 \mathrm{st}$ & 1 & 40 & 25 & 25 & 15 & 5 & 10 & 5 & 5 & 10 & 25 & 40 & 30 \\
\hline 1st & 2 & 30 & 20 & 10 & 10 & 5 & 5 & 5 & 10 & 10 & 20 & 35 & 25 \\
\hline 2nd & 3 & 40 & 30 & 25 & 15 & 10 & 10 & 5 & 5 & 15 & 30 & 30 & 30 \\
\hline $2 \mathrm{nd}$ & 4 & 50 & 30 & 15 & 20 & 5 & 10 & 10 & 10 & 20 & 30 & 45 & 35 \\
\hline \multirow[t]{2}{*}{2 nd } & 5 & 45 & 40 & 30 & 20 & 10 & 10 & 5 & 10 & 20 & 35 & 50 & 35 \\
\hline & Installed capacities & 50 & 40 & 30 & 20 & 10 & 10 & 15 & 10 & 20 & 40 & 50 & 40 \\
\hline
\end{tabular}


Example 2 Planning of sectionalizing switches using the key position method

Consider the distribution system in Figure 1b. The rated capacities for main transformers and feeders are assumed to be $600 \mathrm{~A}$ and $300 \mathrm{~A}$, respectively. The installed capacities and six typical load patterns are summarized in Table 2.

Note that only six load patterns are considered in the example for convenience of demonstration. In addition, only the first three typical load patterns appear in the first year. And the last three typical load patterns are assumed to appear in the second year.

In step 1, place 13 switches at 13 candidate switch positions. In step 2, the near-optimal feeder configuration for each typical load pattern is as follows.

$$
\begin{gathered}
\operatorname{SET}_{0}=\left(\mathbf{S}_{7}\right), \operatorname{SET}_{1}=\left(\mathbf{S}_{6}\right), \operatorname{SET}_{2}=\left(\mathbf{S}_{8}\right), \\
\operatorname{SET}_{3}=\left(\mathbf{S}_{5}\right), \operatorname{SET}_{4}=\left(\mathbf{S}_{7}\right), \operatorname{SET}_{5}=\left(\mathbf{S}_{6}\right) .
\end{gathered}
$$

So, $\mathrm{SET}_{\text {open }}=\left(\mathrm{S}_{5}, \mathrm{~S}_{6}, \mathrm{~S}_{7}, \mathrm{~S}_{8}\right)$

There is only one switchable region $\mathrm{AREA}_{1}$ in this example.

$$
\operatorname{AREA}_{1}=\left(\mathrm{L}_{5}, \mathrm{~L}_{6}, \mathrm{~L}_{7}, \mathrm{~S}_{5}, \mathrm{~S}_{6}, \mathrm{~S}_{7}, \mathrm{~S}_{8}\right)
$$

The maximum load of switchable region $\mathrm{AREA}_{1}$ is

$$
\operatorname{LOAD}_{\max }\left(\mathrm{AREA}_{1}\right)=\max [30,20,20,20,30,35]=30
$$

As no transformer or feeder is overloaded, it is not necessary to narrow down AREA $_{1}$.

In step 3, the perforrnance of reconfiguration is satisfactory because there are four feeder configurations.

In step $4, N_{\mathrm{SW}}=13>S W_{\min }=2$. Therefore, we go to step 5 to decrease the total number of switches. As switches $S_{1}, S_{2}, S_{3}, S_{4}, S_{9}, S_{10}$ and $S_{11}$ never appear in $\mathrm{SET}_{i}(i=0,1, \ldots, 5)$, they can be removed. Note that switches (circuit breakers) $S_{0}$ and $S_{12}$ cannot be removed because we need a circuit breaker at the head of a feeder.

In step 3, the performance of reconfiguration is satisfactory and $N_{\mathrm{sw}}=6>S W_{\min }=2$ in step 4 .

In step 5 , switch $S_{8}$ is selected as the switch to be removed as switch $\mathrm{S}_{8}$ appears only in $\mathrm{SET}_{2}$. Note that the near-optimal feeder configuration $\mathrm{SET}_{2}=\left(\mathrm{S}_{8}\right)$ for load pattern 2 is lost because there is no switch placed at the candidate switch position $\mathrm{S}_{8}$.

In step 3, the performance of reconfiguration is satisfactory and $N_{\mathrm{SW}}=5>S W_{\min }=2$ in step 4 .

In step 5 , switch $S_{5}$ is selected as the switch to be removed.

In step 3, the performance of reconfiguration is not satisfactory as there are only 2 feeder configurations which can be used. Therefore, we go to step 6 .

In step 6, $N_{\mathrm{SW}}=4<S W_{\max }=13$. Therefore, we go to step 7 to restore switch $S_{5}$ and stop. The result is summarized in Figure 1b.

\section{The feeder network refinement algorithm}

As the objective in the feeder planning algorithm in Section $V$ is to minimize the feeder length which is proportional to the investment cost, it may happen that the resultant feeder network is very loosely connected, resulting in only a very limited number of possible configurations available in future system operation. This may severely damage the performance of reconfiguration in system operation. The following procedures are recommended in order to increase the possible configurations.

Step 1. Designate the longest edge as the candidate edge.

Step 2. Select a load point in the middle of the candidate edge as the candidate load point.

Step 3. Connect the candidate load point to a load point on another edge which is closer to the candidate load point.

The above procedures are repeated until the number of configurations is enough.

\section{Applications of the proposed method}

The proposed heuristic search algorithms have been applied to plan a distribution system as shown in Figure 4. The estimated cost for constructing a distribution substation is $\$ 200000$. The estimated cost for constructing a $500 \mathrm{kVA}$ main transformer is $\$ 370000$. The cost of constructing a primary feeder $(336 \mathrm{kCmil}$ aluminum conductors) is estimated at $\$ 40000 / \mathrm{km}$. The cost of each remotely controlled switch is estimated at $\$ 2000$. It is assumed that the operators are satisfied with the performance of reconfiguration if there are more than 100 possible configurations. The total number of substations, $N_{\mathrm{SUB}}$, main transformers, $N_{\mathrm{TR}}$, feeders, $N_{\mathrm{FE}}$, and sectionalizing switches, $N_{\mathrm{SW}}$, feeder length, $L_{\mathrm{f}}$, and total investment cost, $C_{\mathrm{t}}$, of the distribution plans obtained by applying the proposed algorithms are summarized in Table 3. It is observed from the results in Table 3 that the distribution plan with two substations is superior to the other plans because it has the lowest investment cost.

\section{Conclusions}

In this paper, the distribution planning problem is divided into three subproblems: the substation planning problem, the feeder planning problem and the sectionalizing switch planning problem. Heuristic search algorithms are developed for the three subproblems. A major feature of the proposed planning algorithm is that the need for network reconfiguration in future system operation is taken into account. From the results of this work, it is concluded that proper distribution plans can be obtained in a very efficient manner by the proposed algorithms. The following specific conclusions can be made based on the results from this work.

(1) Several substation plans with different numbers of substations are recommended by the proposed algorithm. The system planner can choose one among the various substation plans based on his own need.

(2) For the purpose of feeder reconfiguration, the feeder

Table 3. Summary of the distribution plans

\begin{tabular}{llllll}
\hline$N_{\text {SUB }}$ & $N_{\text {TR }}$ & $N_{\text {FE }}$ & $N_{\text {SW }}$ & $L_{\mathrm{f}}(\mathrm{km})$ & $C_{\mathrm{t}}$ \\
\hline 1 & 5 & 10 & 33 & 80.2 & 6004564 \\
2 & 5 & 10 & 23 & 65.7 & 5606476 \\
3 & 6 & 12 & 22 & 61.3 & 6131452 \\
4 & 6 & 12 & 20 & 59.4 & 6253860 \\
5 & 7 & 14 & 23 & 59.6 & 6975068 \\
6 & 8 & 16 & 20 & 58.4 & 7626196 \\
\hline
\end{tabular}


network must be planned as a loop-type structure. In system operation, some tie switches in the loop-type network are opened in order to make the system radial.

(3) In the planning of the feeder network and sectionalizing switch, the principal objective is to minimize the investment cost. In addition, the number of possible configurations must be as large as possible as we need to perform feeder reconfiguration in future system operation for the purposes of load balancing and loss reduction under ever-changing loading conditions.

(4) In the case of a fault event, sectionalizing switches can be used to locate the fault, to isolate the faulted section and then to restore the electricity service to unfaulted sections. In the present work, we try to make the number of possible configurations as large as possible. In this way, we are able to restore the electricity service to unfaulted sections from neighbouring feeders through the switching operations of the sectionalizing switches.

\section{Acknowledgement}

Financial support given to this work by the National Science Council of R.O.C. under contract number NSC82-0404-E002-098 is appreciated.

\section{References}

1 Gonen, $\mathbf{T}$ Electric power distribution system engineering McGraw-Hill (1986)

2 Gonen, $\mathbf{T}$ and Ramirez-Rosado, I J 'Optimal multi-stage planning of power distribution systems' IEEE Trans. Power Deliv. Vol PWRD-2 (1987) pp 512-519

3 Hsu, $\mathbf{Y} \mathbf{Y}$ and Chen, $\mathbf{J} \mathbf{L}$ 'Distribution planning using a knowledge-based expert system' IEEE Trans. Power Deliv. Vol 5 No 3 (1990) pp 1514-1519

4 Youssef, H F and Hackam, R 'Dynamic solution of distribution planning in intermediate time range' IEEE Trans. Power Deliv. Vol 3 No 1 (1988) pp 341-348

5 Youssef, H K, Hackam, R and Abu-El-Magd, M A 'Novel optimization model for long range distribution planning' IEEE Trans. Power Appar. Syst. Vol PAS-104 (1985) pp 3195-3202

6 Quintana, V H, Temraz, H K and Hipel, K W'Two-stage power system distribution planning algorithm' IEE Proc. C Vol 140 (1993) pp 17-29

7 Partanen, J 'A modified dynamic programming algorithm for sizing, locating, and timing of feeder reinforcements' IEEE Trans. Power Deliv. Vol 5 (1990) pp 277-283

8 Chen, $\mathbf{J} \mathbf{L}$ and $\mathbf{H s u}, \mathbf{Y} \mathbf{Y}$ 'An expert system for load allocation in distribution expansion planning' IEEE Trans. Power Deliv. Vol 4 (1989) pp 1910-1918
9 Grawford, D M and Holt, Jr S B 'A mathematical optimization technique for locating and sizing distribution substation and deriving their optimal service areas' IEEE Trans. Power Appar. Syst. Vol 94 (1975) pp 230-235

10 El-Kady, M A 'Computer-aided planning of distribution substation and primary feeders' IEEE Trans. Power Appar. Syst. Vol 103 (1984) pp 1183-1189

11 Wall, D L, Thompson, G L and Northcote-Green, J E D 'An optimization model for planning radial distribution network' IEEE Trans. Power Appar. Syst. Vol 98 (1979) pp 1061-1067

12 Sun, D I, Farris, D R, Cote, P J, Shoults, R R and Chen, MS 'Optimal distribution substation and primary feeder planning via the fixed charge network formulation' IEEE Trans. Power Appar. Syst. Vol 101 (1982) pp 602-609

13 Mikic, $\mathbf{O} \mathbf{M}$ 'Mathematical dynamic model for long-term distribution system planning' IEEE Trans. Power Syst. Vol 1 (1986) pp 34-40

14 Ramirez-Rosado, I $\mathbf{J}$ and Gonen, $\mathbf{T}$ 'Pseudodynamic planning for expansion of power distribution systems' IEEE Trans. Power Syst. Vol 6 (1991) pp 245-254

15 Willis, H L, Tram, H N and Powell, R W'Substation siting and capacity selection based on diversity maximization' IEEE Trans. Power Syst. Vol 2 (1987) pp 692-699

16 Nara, K, Satoh, T, Aoki, $K$ and Kitagawa, $M$ 'Multi-year expansion planning for distribution systems' IEEE Trans. Power Syst. Vol 6 (1991) pp 952-958

17 Aoki, K, Kuwabara, H, Satoh, $T$ and Kanezashi, $M$ 'An efficient algorithm for load balancing of transformers and feeders by switch operations in large scale distribution systems' IEEE Trans. Power Deliv. Vol PWRD-3 (1988) pp 1865-1872

18 Hsu, Y Y, Jwo-Hwu, Y, Liu, S S, Chen Y W, Feng, H C and Lee, $Y \mathbf{M}$ 'Transformer and feeder load balancing using a heuristic search approach' IEEE Trans. Power Syst. Vol 8 (1993) pp 184-190

19 Wagner, T P, Chikhani, A Y and Hackam, R 'Feeder reconfiguration for loss reduction: an application of distribution automation' IEE Trans. Power Deliv. Vol 6(1991) pp 1922-1933

20 Broadwater, R P, Khan, A H, Shaalan, H E and Lee, R E 'Time varying load analysis to reduce distribution losses through reconfiguration' IEEE Trans. Power Deliv. Vol 8 (1993) pp 294-300

21 Shirmohammadi, $\mathbf{D}$ 'Service restoration in distribution networks via network reconfiguration' IEEE Trans. Power Deliv. Vol 7 (1992) pp 952-958

22 Hsu, Y Y, Huang, H M, Kuo, H C, Peng, S K, Chang, C W, Chang, K J, Yu, H S, Chow, C E and Kuo, R T 'Distribution system service restoration using a heuristic search approach' IEEE Trans. Power Deliv. Vol 7, (1992) pp 734-740

23 Hsu, Y Y and Jwo-Hwu, Y 'Planning of distribution feeder reconfiguration with protective device coordination' IEEE Trans. Power Deliv. Vol 8 No 3 (1993) pp 1340-1347 